\title{
0577 NINETEEN YEARS OF PREVENTION POLICIES: THE IMPACT OF THE TARGETS ON NON INTENTIONAL INJURIES ESTABLISHED IN THE HEALTH PLAN FOR CATALONIA
}

V Martinez-Beneyto*, J M Suelves, P Brugulat, R Tresserras, A Plasencia, A Medina, C Cabezas Correspondence: Department of Health, Government of Catalonia, Travessera de les Corts, 13108028 Barcelona - Spain, 08028 Spain, Spain

\subsection{6/ip.2010.029215.577}

Context In 1991, the Department of Health of the Government of Catalonia (autonomous region in Spain, population 7.3 million), following the recommendations of the WHO European Regional Office, started an innovative health planning scheme, with well established health and risk reduction targets for two main periods, 1991-2000 and 2001-2010. In Catalonia, as in other European countries, injuries produced by non intentional causes are one of the main public health problems, account for a substantial proportion of morbidity and avoidable mortality.

Objectives To analyse the evolution of the selected indicators in order to evaluate the impact of the policies implemented and assess the targets of the periodical Health Plans on injury prevention and control in Catalonia.

Methods and products To present the main strategies on injury prevention and control, the elements of the 12 health and risk reduction targets, with the quantification of their indicators, previously established. It shows, also, the 47 operative targets developed during the five periods of the Health Plan. The values of the indicators used to know the evolution and the attainment of each formulated target are detailed by tables and figures.

Discussion During a wide planning period, interventions developed have contributed to the attainment of the health targets on non intentional injuries, measured and assessed. The trends of mortality and morbidity due to non intentional injuries evolved positively during this period. The four targets established for the year 2000 were achieved, and five of the eight targets for 2010 evolves positively. 